\title{
Peritoneal Cavity
}

National Cancer Institute

\section{Source}

National Cancer Institute. Peritoneal Cavity. NCI Thesaurus. Code C12769.

The lower part of the abdomen that contains the intestines (the last part of the digestive tract), the stomach, and the liver. It is bound by thin membranes. 